\title{
Education on Middle East Respiratory Syndrome and Personal Hygiene Practices of Medical Students
}

\author{
Min Jeong $\mathrm{Kim}^{1} \cdot$ Sang Yeoup Lee ${ }^{2}$ \\ ${ }^{1}$ Department of Medical Education, Kosin University College of Medicine, Busan; ${ }^{2}$ Department of Medical Education, Pusan National University School of \\ Medicine, Yangsan, Korea
}

\begin{abstract}
The purpose of this study was to inquire into the knowledge of medical students on the Middle East respiratory syndrome (MERS) and evaluate whether infection prevention education impacts students' level of knowledge and individual hygiene practices. This study also investigated the route by which medical students obtain disease-related information. The study involved a survey conducted in August of 2015 at two medical schools in Busan. In the first year to fourth year, a total of 345 students are enrolled (111 students in A school and 234 students in B school). Before the study was carried out, university A performed infection prevention education related to MERS, but $B$ did not. We used self-developed questionnaires to survey the demographic characteristics, routes of acquisition of MERS information, degree of knowledge of MERS, educational satisfaction, and personal hygiene practices before and after education. Knowledge level differences according to gender and year in school were not statistically significant. Students obtained their information about MERS from various news media sources and the Internet, and through social network sites. Students practiced sanitary control behaviors in an average of 2.2 manners (standard deviation=0.95). The level of knowledge of MERS revealed a positive correlation with the frequency and total numbers of personal hygiene practices. This finding suggests that the infection prevention education program played a role in knowledge acquisition and personal hygiene practices for the medical students. In order to provide accurate and reliable knowledge of disease and preventive health behavior to medical students, continuous and well-planned education programs are necessary.
\end{abstract}

Keywords: Coronavirus infections, Medical students, Hygiene

\section{Corresponding author}

Sang Yeoup Lee

Department of Medical Education,

Pusan National University School of

Medicine, 49 Busandaehak-ro,

Mulgeum-eup, Yangsan 50612, Korea

Tel: $+82-51-510-8124$

Fax: +82-51-510-8126

E-mail: saylee@pnu.edu

http://orcid.org/0000-0002-3585-9910

Received: March 30, 2016

1st revised: May 16, 2016

2nd revised: June 8,2016

Accepted: June 10, 2016

\section{서 론}

2015년 5월 한국에서 중동호흡기증후군(Middle East respiratory syndrome, $\mathrm{MERS}=$ 메르스) 첫 감염 환자가 확진되었다. 이후 총 186 명의 메르스 확진자가 발생하였고 38 명이 사망하였다 (Ministry of Health and Welfare, 2015). 이전에 경험하였던 중증호 흡기증후군(severe acute respiratory syndrome, SARS=사스)이나 신종플루와는 달리 메르스는 병원 내 감염으로, 확진자들이 의료기 관 내 방문 및 체류환자들이 대부분이었다는 사실은 우리나라의 의료이용문화와 병원 감염관리의 취약함을 인식시켜 주었다(Lee, 2015). 메르스의 또 한 가지 특징은 확진자의 $20 \%$ 정도가 의사, 간호사와 응급 이송 요원 등 보건의료인이라는 사실이다(Kim, 2015). 우리나라에서 메르스는 최초 확진자를 제외하고는 사람 간의
밀접접촉으로 인한 감염이 대부분이었다. 현재까지 알려진 전파양 상은 의료기관 내에서 비말이나 바이오에어로졸 및 직접 접촉에 의한 것이 대부분이었으나, 세계보건기구(World Health Organization, $\mathrm{WHO}$ )는 메르스 환자에 대한 기관지내시경, 객담검사, 기관삽 관제거, 기도흡인 등의 에어로졸 생성 시술 시 공기를 통한 전파의 가능성을 배제할 수 없으며 병원 내에서 이러한 시술 시 주의할 것을 권고하고 있다(Kim, 2015). 보건 의료인은 환자를 직접 진단하 고 치료해야 하는 업무상 감염에 노출될 확률이 높아서, 환자나 보호자들에게는 감염원이 될 수도 있다. 따라서 보건 의료인이 감염 성 질환에 대한 정확한 지식을 가지고 감염예방관리를 하는 것은 환자나 보호자뿐 아니라 스스로의 감염으로부터 지키기 위해 필요 하다.

의과대학생들은 교육과정에서 많은 시간을 임상실습에 할애하고 
있으며 다양한 임상실습현장에서 많은 환자들과 접촉할 수 있다. 메르스 유행 당시 각 병원들은 병원을 방문하는 환자 및 환자의 보호자, 병문안을 하러 온 모든 방문객의 체온측정과 방문이유, 개인 신상을 확인하는 등 감염의 전파를 막기 위한 조치를 취하였다. 그러나 다른 방문객들과는 달리 의과대학생들은 자유롭게 병원출입 과 이동이 가능하며, 임상실습 중에는 진료실이나 검사실에서 전문 보건 의료인과 마찬가지로 감염위험에 노출될 가능성이 높아 스스로 의 안전문제뿐만 아니라 감염전파의 위험성도 함께 가지고 있다. 따라서 의과대학생들은 전염성 질환에 대한 전문지식을 통해 감염질 환의 예방 및 대처능력을 키우는 것이 반드시 필요하다. Herbert et al. (2013)은 의과대학생들의 위생지침에 대한 지식과 준수도 간의 관련성을 본 연구에서 스스로 위생지침에 대한 지식이 높다고 평가한 학생 수에 비하여 실제로 지침서나 $\mathrm{WHO}$ 의 기준에 맞게 위생지침을 수행하는 학생 수는 매우 적어, 지식수준과 실제 수행도 간의 괴리가 있음을 보여주었다. Calabro et al. (2000)는 사전 시험손씻기 실습-강의-증례토론-사후 시험의 순서로 감염관리 교육프 로그램을 시행하고 교육프로그램이 끝난 직후와 2년이 경과한 후에 감염관리에 대한 지식수준을 비교한 연구를 시행하였다. 그 결과 프로그램 시행 직후에 학생들의 감염관리 관련 지식수준이 현저하게 향상되었지만 2년이 경과한 후에는 그 수준이 다시 저하되어 교육프 로그램에 참여하지 않은 학생들과 비슷한 수준이었다는 결과를 도출 하고 감염관리에 대한 교육은 규칙적으로 반복되어야 함을 강조하였 다. 그 외에도 의과대학생들의 손씻기를 포함한 감염예방을 위한 위생관리 실천도를 보기 위한 연구에서, 대부분의 의과대학생들이 감염예방에 대한 사전지식의 여부에 상관없이 감염예방수칙에 대한 실천도가 낮으며 반복적이며 체계적인 감염예방교육이 필요하다고 주장하였다(Al Kadi \& Salati, 2012; Barroso et al., 2016; Melenhorst et al., 2009). 지금까지 국내에서 감염예방과 관리에 대한 연구들은 병원에서 근무하고 있는 의료인을 대상으로 한 연구 가 대부분이었으며 간호대학생들을 대상으로 한 연구는 있으나 의과대학생을 대상으로 한 연구는 거의 없었다. 이에 본 연구에서는 의과대학 재학생들을 대상으로 메르스 관련 지식수준과 감염관리 를 위한 개인위생 실천도를 조사하고 감염예방교육 전후의 개인위 생 실천도를 비교하여 향후 지속적인 감염예방 교육프로그램 개발 의 필요성을 확인하고자 하였다.

또한 이번 연구에서 의과대학 학생들이 질병 관련 정보와 지식을 획득하는 경로에 대하여 알아보았다. 메르스 발병 초기 대응의 실패 로 발생자 수가 사우디아라비아에 이어 세계에서 두 번째로 높은 나라라는 오명을 쓰게 되면서 국민들은 지속적인 관심을 가지고 매일 같이 쏟아지는 언론보도에 귀를 기울였다. 이처럼 대중의 지속 적인 관심을 갖게 되는 이슈에 대하여 관련 정보는 전적으로 언론의 보도나 인터넷을 통하여 획득하게 되는 경향이 있으며, 객관적이지 못한 정보와 지식을 무비판적으로 수용할 경우 많은 사회적인 혼란
을 유발할 수 있다. 저자들은 근거중심의학 교육과정을 이수한 의과 대학생들이 새로운 질병 관련 정보를 획득하는 주된 경로를 알아보 고 본 대학의 근거중심의학 교육의 방향을 수립하는 하나의 자료로 이용하고자 하였다.

\section{연구대상 및 방법}

본 연구는 2015년 8월에 부산지역의 A, B의과대학 의학과 1학년 부터 4학년 학생들 중 연구목적 및 절차에 대하여 설명을 듣고 동의 한 학생을 대상으로 설문을 진행하였다. 설문의 내용은 인구사회적 특성 2개 문항, 메르스에 대한 정보 습득경로 2개 문항, 메르스 관련 지식수준 6 개 문항, 메르스 관련 교육이수 여부 1 개 문항, 교육 전 개인 위생관리행태 1 개 문항, 교육 후 개인 위생관리행태 1 개 문항, 교육만족도 1 개 문항으로, 총 14 개 문항으로 구성하였다. 메르스 관련 지식수준은 메르스의 원인균, 잠복기, 감염경로, 확진을 위한 검체의 채취시기, 한국에서 메르스의 치명률과 밀접 접촉자의 정의 등 6 개 문항에 대해 각 문항의 정답을 맞힐 경우 1점을 부여하였다. 각 항목에 대한 정답은 질병관리본부에서 발표한 자료에 근거하였으 며 감염경로와 밀접 접촉자의 정의는 다중 응답하도록 하였다. 메르 스에 대한 최초 정보 습득경로와 이후 메르스 관련 지식 습득경로는 의학 관련 정보를 습득할 수 있는 주요 경로인 뉴스나 신문 등의 대중매체, 인터넷이나 소셜네트워크서비스(social network service, $\mathrm{SNS})$, 의학저널, 강의와 동료 및 선후배의 5 개 중 본인의 정보 습득경 로에 대해 다중 응답하도록 하였다. 개인 위생관리행태는 일반적인 호흡기질환 예방수칙과 질병관리본부에서 발표한 의료인 감염예방 지침사항으로 항목을 구성하여 손 씻기, 기침이나 재채기를 할 때 휴지나 소매 끝부분으로 입과 코를 가리기, 일반 마스크 착용, N95 마스크 착용, 고글 또는 안면보호구 착용의 5 개 위생관리행태 중 본인이 사용하고 있는 관리행태에 대해 다중 응답하도록 하였다. 다중 응답문항의 경우 보기에 제시한 해당 항목에 체크를 할 경우 1 점을 부여하였으며, 하지 않을 경우 0 점을 부여하였다. $\mathrm{A}$ 의과대학 의 경우 연구를 수행하기 전에 이미 의학과 1 학년부터 의학과 4학년 학생을 대상으로 메르스에 대한 자체 감염예방교육을 하였으며 B의 과대학의 경우 대학 차원의 교육을 시행하지는 않았다. 메르스에 대한 자체 감염예방교육은 메르스의 발생상황과 감염경로, 증상, 진단방법 등의 개요와 감염예방 및 잠재적 노출자에 대한 관리에 대한 내용이 포함되어있었다. A대학의 학생들의 경우 교육을 받은 후에 교육만족도와 감염예방을 위해 시행한 개인 위생행태에 대하여 동일한 5 개 항목 중 다중 응답하도록 하였다. 교육만족도는 5점 Likert 척도로 측정하였다.

본 연구의 검증은 다음과 같은 순서로 진행되었다. 먼저 인구사회 적 특성에 따른 메르스 관련 지식수준의 차이가 있는지 확인하였으 며, 이는 $\mathrm{t}$-검정과 analysis of variance를 통해 확인하였다. 메르스 
에 대한 감염예방교육 유무에 따른 지식수준의 차이를 카이제곱검정 과 두 표본 $\mathrm{t}$-검정을 통해 확인하였다. 최초 정보 습득경로 및 정보 습득 이후 메르스 관련 지식 습득경로에 대해서는 빈도분석을 실시 하였다. 다음으로 학생들이 사용하고 있는 위생관리행태를 파악하 기 위한 빈도분석을 실시하였으며, 메르스 관련 지식수준과 위생관 리행태 사이의 관계성을 살펴보기 위해 상관분석을 실시하였다. 메 르스 교육효과에 대한 검증을 실시하였으며, 이와 관련하여 $\mathrm{A}$ 대학 의 경우 학교 차원의 교육이 있었으나, B대학의 경우 학교 차원에서 교육이 이루어진 것이 아니기 때문에 $\mathrm{A}$ 대학만을 대상으로 분석하였 다. 분석방법으로는 만족도 수준에 대한 기술 통계치를 살펴보았으 며, 교육 전후 예방관리행태의 차이를 살펴보기 위해 $\mathrm{t}$-검정을 실시 하였다. 모든 통계분석은 통계패키지 PASW SPSS Statistics ver. 18.0 (SPSS Inc., Chicago, IL, USA)을 사용하여 분석하였다.

\section{결 과}

\section{1. 인구사회적 특성 및 교육 유무에 따른 메르스 관련 지식수준의 차이}

각 대학별로는 A대학 120 명, B대학 237명으로부터 설문지가 수집되었다. 이 중 응답이 불성실한 12 명을 제외한 345 명의 자료를 분석하였다. 대상자의 성별은 남학생 230명(66.7\%), 여학생 115명
(33.3\%)이며, A의과대학의 경우 1학년 29명(26\%), 2학년 23명 (21\%), 3학년 30명(27\%), 4학년 29명(26\%), B의과대학은 1학년 116명(49\%), 2학년 23명(10\%), 3학년 68명(28\%), 4학년 30명 (13\%)이다. 응답자의 인구사회적 특성에 따른 메르스 관련 지식수 준의 차이는 Table 1 과 같다. 성별에 따른 지식수준 차이는 여학생의 평균이 남학생의 평균보다 높았으나 통계적으로 유의미하지는 않았 다. 4학년의 평균이 1.42점(standard deviation $[\mathrm{SD}]=1.28)$ 로 가장 높게 나타났으나, 학년 간 지식수준의 차이가 통계적으로 유의하지 않았다. 대학별 메르스 관련 지식수준을 비교해 본 결과 한국에서의 메르스 치사율을 제외한 나머지 항목에서 유의한 차이가 없었다. 메르스 관련 지식의 총점은 $\mathrm{A}$ 의과대학이 B의과대학에 비하여 높았 으나 통계적으로 유의하지는 않았다(Table 2).

\section{2. 메르스에 대한 정보 습득경로}

학생들이 메르스에 대해 최초로 정보를 습득하는 경로는 345 명으 로부터 350개의 응답이 수집되었다. 각각 언론매체 229명(66.4\%), 인터넷과 SNS 100 명(29.0\%), 문헌(저널)검색 2명(0.6\%), 수업 2명 $(0.6 \%)$, 주변 사람들 17 명(4.9\%)이었다. 최초 정보 습득 이후 지속 적으로 메르스에 대한 정보를 습득한 경로는 345명으로부터 662개 응답이 수집되었으며, 각각 언론매체 208명(60.3\%), 인터넷과 SNS 240명(69.6\%), 문헌(저널)검색 61명(17.7\%), 수업 72명(20.9\%),

Table 1. Level of knowledge regarding MERS (Middle East respiratory syndrome) by demographic characteristics

\begin{tabular}{lccc}
\hline \multicolumn{1}{c}{ Variable } & No. & Mean \pm standard deviation & p-value \\
\hline Gender & & & \\
Male & 230 & $1.26 \pm 1.08$ & 0.80 \\
Female & 115 & $1.29 \pm 1.01$ & \\
Year in medical school & & & \\
1 & 143 & $1.13 \pm 0.94$ & \\
2 & 47 & $1.23 \pm 1.00$ & $1.39 \pm 1.08$ \\
3 & 98 & $1.42 \pm 1.28$ & \\
4 & 57 & & \\
\hline
\end{tabular}

Table 2. Differences in knowledge about MERS between the two medical schools by MERS education exposure

\begin{tabular}{|c|c|c|c|}
\hline \multirow{2}{*}{ Variable } & \multicolumn{2}{|c|}{ Medical school } & \multirow{2}{*}{ p-value } \\
\hline & MERS lecture $(n=111)$ & No MERS lecture $(n=234)$ & \\
\hline \multicolumn{4}{|l|}{ Questions about MERS knowledge } \\
\hline Causative virus? & $11(9.9)$ & $23(9.8)$ & 0.981 \\
\hline Incubation period? & $64(57.7)$ & 99 (42.3) & 0.008 \\
\hline Transmission path? & $4(3.6)$ & $10(4.3)$ & 0.768 \\
\hline Diagnostic test timing? & $30(27.0)$ & $69(29.5)$ & 0.637 \\
\hline Mortality in Korea? & $40(36.0)$ & $37(15.8)$ & $<0.001$ \\
\hline Definition of close contacts? & $15(13.5)$ & $35(15.0)$ & 0.722 \\
\hline Knowledge score (total 6) & $1.5 \pm 1.1$ & $1.2 \pm 1.0$ & 0.010 \\
\hline
\end{tabular}

Values are presented as number $(\%)$ or mean \pm standard deviation.

MERS, Middle East respiratory syndrome. 
Table 3. Sources of information about MERS

\begin{tabular}{|c|c|c|}
\hline \multirow{2}{*}{ Sources } & \multicolumn{2}{|c|}{ Medical school } \\
\hline & MERS lecture $(n=111)$ & No MERS lecture $(n=234)$ \\
\hline \multicolumn{3}{|l|}{ First source } \\
\hline Mass media & $69(62.2)$ & $160(68.4)$ \\
\hline Internet and SNS & $39(35.1)$ & $61(26.1)$ \\
\hline Literature search & $0(0.0)$ & $2(0.9)$ \\
\hline Class & $1(0.9)$ & $1(0.4)$ \\
\hline Other people & $7(6.3)$ & $10(4.3)$ \\
\hline \multicolumn{3}{|l|}{ Subsequent sources } \\
\hline Mass media & $65(58.6)$ & $143(61.1)$ \\
\hline Internet and SNS & $74(66.7)$ & 166 (70.9) \\
\hline Literature search & $15(13.5)$ & 46 (19.7) \\
\hline Class & $19(17.1)$ & $53(22.6)$ \\
\hline Other people & $12(10.8)$ & $69(29.5)$ \\
\hline
\end{tabular}

Values are presented as number $(\%)$.

MERS, Middle East respiratory syndrome; SNS, social network services.

Table 4. Relationship between knowledge level and hygiene practice ( $N=333$ )

\begin{tabular}{|c|c|c|c|c|c|c|c|}
\hline \multirow{2}{*}{ Variable } & \multicolumn{7}{|c|}{ Knowledge level } \\
\hline & 1 & 2 & 3 & 4 & 5 & 6 & 7 \\
\hline Level of knowledge & - & & & & & & \\
\hline Hand washing and sterilization & $0.12^{*}$ & - & & & & & \\
\hline General mask & $0.20^{* * *}$ & 0.05 & - & & & & \\
\hline N95 mask & $0.13^{*}$ & $-0.15^{* * *}$ & -0.01 & - & & & \\
\hline Goggles and face protector & $0.13^{*}$ & -0.03 & $0.13^{*}$ & $0.28 * * *$ & - & & \\
\hline Cover mouth and nose when coughing and sneezing & $0.23^{* * *}$ & $0.15^{* *}$ & 0.09 & 0.08 & $0.13^{*}$ & - & \\
\hline No. of hygiene behaviors & $0.34^{* * *}$ & $0.28 * * *$ & $0.61 * * *$ & $0.45^{* * *}$ & $0.43^{* * *}$ & $0.66^{* * *}$ & - \\
\hline Mean \pm standard deviation & $1.27 \pm 1.05$ & $0.94 \pm 0.23$ & $0.53 \pm 0.50$ & $0.18 \pm 0.38$ & $0.03 \pm 0.17$ & $0.52 \pm 0.50$ & $2.20 \pm 0.95$ \\
\hline
\end{tabular}

${ }^{*} p<0.05 .{ }^{* *} p<0.01$. ${ }^{* *} p<0.001$.

Table 5. Changes in personal hygiene behavior before and after education $(N=83)$

\begin{tabular}{|c|c|c|c|}
\hline \multicolumn{2}{|l|}{ Variable } & \multirow{2}{*}{$\begin{array}{c}\text { Value } \\
0.95 \pm 0.22\end{array}$} & \multirow{2}{*}{$\frac{p \text {-value }}{0.71}$} \\
\hline Hand washing and sterilization & Before & & \\
\hline & After & $0.94 \pm 0.24$ & \\
\hline \multirow[t]{2}{*}{ General mask } & Before & $0.58 \pm 0.50$ & 0.01 \\
\hline & After & $0.70 \pm 0.46$ & \\
\hline \multirow[t]{2}{*}{ N95 mask } & Before & $0.13 \pm 0.34$ & 0.21 \\
\hline & After & $0.18 \pm 0.39$ & \\
\hline \multirow[t]{2}{*}{ Goggles and face protector } & Before & $0.01 \pm 0.11$ & 0.18 \\
\hline & After & $0.05 \pm 0.22$ & \\
\hline \multirow[t]{2}{*}{ Cover mouth and nose when coughing and sneezing } & Before & $0.51 \pm 0.50$ & 0.01 \\
\hline & After & $0.63 \pm 0.49$ & \\
\hline \multirow[t]{2}{*}{ No. of personal hygiene practice } & Before & $2.17 \pm 0.92$ & 0.00 \\
\hline & After & $2.49 \pm 1.02$ & \\
\hline
\end{tabular}

Values are presented as mean \pm standard deviation.

주변 사람들 81 명(23.5\%)이었다(Table 3).

\section{3. 감염예방을 위한 위생관리행태}

메르스 예방을 위한 위생관리행태의 경우 응답을 하지 않은 12 명
을 제외한 333명으로부터 732개의 응답이 수집되었다. 사용하고 있는 위생관리행태를 살펴보면 각각 손 씻기 또는 손 소독 314명 (94.3\%), 마스크 착용 175명(52.6\%), N95 마스크 착용 60명 (18.0\%), 고글 또는 안면보호구 착용 10 명(3.0\%), 기침이나 재채기 
를 할 경우 화장지나 손수건으로 입과 코를 가리기 173명(52.0\%)이 었으며, 1 인당 예방관리행태의 수는 평균 2.20 개 $(\mathrm{SD}=0.95)$ 였다.

메르스 관련 지식수준과 위생관리행태 사이의 관계성을 살펴본 결과 지식수준은 모든 위생관리행태 및 사용하고 있는 관리행태의 수와 유의미한 정적 상관이 있는 것으로 나타났다(Table 4). 이는 메르스 관련 지식수준이 높을수록 각각의 관리행태를 더 많이 함을 의미하며, 동시에 사용하고 있는 예방관리행태 수가 더 많음을 의미 한다.

\section{4. 교육효과성}

$\mathrm{A}$ 대학의 메르스 관련 교육에 대한 교육만족도와 교육 전후 위생 관리행태 변화를 살펴보았다. 설문 응답자 111 명 중 83명이 메르스 관련 교육을 받았으며, 교육에 대한 만족도는 평균 $3.37(\mathrm{SD}=6.12)$ 이었다. 교육 전후 위생관리행태 변화를 살펴보면 교육 후 마스크를 착용하는 경우가 증가하였고, 기침이나 재채기를 할 경우 화장지나 손수건으로 입과 코를 가리기와 1 인당 예방관리행태 수가 통계적으 로 유의미하게 증가하였다(Table 5).

\section{고 찰}

이번 연구결과에서 의과대학 학생들의 메르스 관련 지식수준을 분석해 본 결과 학생들의 메르스 관련 지식수준은 낮은 것으로 나타 났다. 모든 학년에서 학생 개개인이 메르스에 대한 정확한 지식을 가지고 있는 항목은 6가지 중 평균 두 가지 미만으로 의과대학생들이 라고 하더라도 메르스 관련 의학지식이 매우 미흡함을 알 수 있었다. 메르스 관련 지식 중에서는 특히 감염경로에 대한 학생들의 지식수 준이 낮았다. 그러나 감염경로에 대하여 사람 간 직접 접촉에 의한 전파 가능성만 인정하고 있는 보건 당국에 비해 일부 전문가들은 비말 전파와 병원 내 공기 전파의 가능성을 주장하는 등 정확한 감염경로에 대한 혼돈이 있었던 점을 고려할 때, 향후 감염질환의 경로에 대한 과학적 검토와 역학 현황분석을 통한 차단과 격리 범위 에 대한 명확한 기준을 제시하는 것이 필요하다.

의과대학생들이 최초로 질병에 대한 정보를 얻은 주된 경로는 뉴스 등의 언론매체였으며 이후 지속적으로 메르스 관련 정보를 얻기 위하여 사용한 방법은 인터넷 검색과 SNS, 언론매체 순이었다. 이에 비하여 문헌을 검색하거나 학교수업을 통하여 정보를 얻었다는 반응은 매우 적은 편이었다. 일반적으로 질병에 관한 정보는 의료기 관보다는 텔레비전, 신문, 인터넷과 같은 미디어에 의해서 개인에게 전달되는 경향이 높으며 최근에는 개인 및 단체의 활발한 SNS 이용 에 힘입어 이를 통한 의료정보의 전달이 늘어나고 있다. 미디어를 통한 질병정보의 전달은 의료정보에 접근을 용이하게 하고, 대중이 질병과 건강에 대해 전문적인 지식을 쉽게 이해하게 함으로서 효과 적으로 대처할 수 있는 능력을 가질 수 있도록 한다. 또 질병의
피해 정도와 예방법, 적합한 치료방법을 습득함으로써 사회적 비용 을 줄이는 데도 기여할 수도 있다는 긍정적인 측면이 있다(Baker et al., 2003). 반면에 의학적으로 검증되지 않은 내용을 여과 없이 제공함으로써 내용의 근거에 대한 정확한 판단을 하기 어려운 대중 에게 잘못된 지식으로 불필요한 불안감을 조성하는 부정적인 영향을 미치기도 한다(Baker et al., 2003; Lee \& Kim, 2009). 실제로 메르 스에 관련된 여러 뉴스들이 특별한 통제 없이 언론사들에 의해 자극 적으로 보도되면서 국민들의 충격과 불안은 극도로 높아지기도 하였 다. 뉴스시간에 보도된 건강의학정보를 근거의학적으로 평가한 논 문에서 오류를 보인 보도가 $40 \%$ 였다는 연구결과는 미디어를 통하 여 질병에 대한 지식을 습득하는 것에 신중을 기해야 한다는 것을 보여준다(Hwang et al., 2006). 쉽고 빠르게 접근할 수 있고 원하는 정보를 선택하여 습득할 수 있다는 장점을 가진 대중매체 이용을 무조건 비판할 수는 없다. 의과대학생들의 근거중심의학적인 수행 능력과 태도에 대한 역량이 요구되는 부분이다. 근거중심의학의 수 행능력은 대부분의 의과대학에서 핵심 역량이고 실제 많은 의과대학 에서 근거중심의학 교육과정이 도입되어 있으며 졸업 후에도 수행을 위한 다양한 교육프로그램에 참여할 수 있는 기회가 주어진다. 의과 대학생들은 교육과정을 통하여 근거중심의 의학 지식습득의 중요성 을 알고 있으며, 의학저널 등의 문헌을 검색할 수 있는 시스템에 쉽게 접근할 수 있는 환경이 조성되어 있음에도 불구하고 대부분이 인터넷이나 SNS를 통하여 질환정보를 받아들이고 있다는 것을 이번 연구결과에서 알 수 있었다. 의과대학생들의 근거중심의학적 수행 에 대한 경험과 태도에 대한 연구에서 학생들의 합리적인 사고와 객관적이고 명확한 분별을 통한 문제해결능력을 함양하는데 근 거중심의학 교육이 도움이 되었으나 사용방법에 대한 지식이 부족하고 지속적으로 근거중심의학적 수행이 요구되는 상황에 노출되지 않는다는 것이 근거중심의학적 수행의 한계라고 지적하 였다(Ghojazadeh et al., 2014). 의과대학생뿐만 아니라 임상의사들 도 실제 임상문제를 다루는 데 있어 적극적으로 근거중심의학적 수행을 하지 못하고 있다. Johnston et al. (2003)은 근거중심의학적 수행이 저조한 원인을 수행방법에 대한 능력뿐만이 아니라 근거중심 의학적인 태도 및 인식에서 찾고 있다. Sackett \& Parkes (1998)도 의과대학 교육과정 및 졸업 후 근거중심의학 교육이 대부분 기술중 심의 교육이기 때문에 임상현장에서 근거중심의학적 접근의 필요성 에 대한 인식이 부족하고 따라서 그것이 필요한 상황임을 인식하여 적용할 수 있는 능력이 부족함을 지적하였다. 근거중심의학 교육의 시기와 적용방법에 대한 메타분석을 통한 연구에서는 의과대학생의 근거중심의학 교육의 적합한 시기를 임상실습시기로 제시하면서도 최근 조기 임상 노출에 대한 장점과 경향을 고려한다면 임상실습 전 단계에서부터 시작할 필요가 있다고 하였다. 또 현재 시행되고 있는 근거중심의학 교육과정이 짧게, 경우에 따라서는 집중과정으 로 편성되어 있으므로 필요성에 대한 인식, 태도 및 수행능력에서의 
단절을 가져올 수 있으므로 의과대학 교육과정 전반에 걸친 나선형 과정(spiral curriculum)으로 설계하는 것이 바람직하다는 주장을 하였다(Maggio et al., 2013). 요약하면, 근거중심의학 교육은 기술 적인 분야에서뿐만 아니라 근거중심의학적인 판단이 필요한 다양한 상황들에 대한 인식과 태도에 대한 교육이 동반되어야 하며 의과대 학 전 교육과정에 걸친 수준별 교육이 필요할 것이다.

학생들은 메르스 예방을 위하여 평균 2.35개의 위생관리행태를 수행하고 있었다. 손 씻기나 손소독의 수행도가 $95 \%$ 이상이었고, 다음으로 마스크 착용과 기침이나 재채기를 할 때 화장지나 손수건 으로 입과 코를 가리기 순이었다. N95마스크를 착용하거나 고글 또는 안면보호구 착용 수행도는 낮은 편이었는데 이는 N95 마스크 나 안면 보호구 등은 전문 보건의료인이 주로 사용하는 것으로 인식 되고 있으며, 메르스가 지역사회 감염의 가능성이 낮으므로 상대적 으로 병원 외부에서는 반드시 필요하지 않다는 생각과 구입이 용이 하지 않기 때문일 것으로 생각된다. 메르스에 대한 지식수준이 높은 학생일수록 상대적으로 각 위생관리 수행도가 높아지고 1 인당 시행 하는 관리행태 수도 많아지는 것으로 나타나 질환에 대한 지식 정도 가 높을수록 위생관리행태가 향상됨을 알 수 있었다. 학생들은 교육 전에 비하여 교육 후에 마스크를 착용하는 경우가 증가하였고, 기침 이나 재채기를 할 경우 화장지나 손수건으로 입과 코를 가리는 경우 가 증가하였다. 또한 전체적인 감염예방 관리행태의 수가 유의미하 게 증가하는 경향을 보여 감염예방교육이 학생들의 위생관리행태에 도움이 됨을 보여주었다. Pittet (2001)는 감염관리행태의 개선을 위해서는 시설 등의 외적 요인보다는 개인의 자세나 태도를 지속적 으로 평가하고 피드백할 수 있는 교육과 동기 부여가 필요함을 지적 하였다. 의과대학생들은 임상실습 교육과정에서 의료인은 아닐지라 도 의료인과 동일한 동선을 가지고 의료행위 시 참관자 혹은 보조자 로서의 역할을 하게 되므로 원내 감염으로부터 스스로를 보호할 수 있어야 할 뿐 아니라 원내 감염의 전파를 막기 위해서도 감염예방 에 대한 교육은 필수적이다. 국내의 의과대학 수련병원들은 다양한 프로그램을 통하여 감염예방교육에 힘을 기울이고 있다. 그러나 이 러한 프로그램들은 대부분 병원에서 근무하는 의료인들과 직원을 대상으로 하고 있다. 의과대학생들은 대부분 임상실습을 시작하기 전 감염예방교육 통하여 감염예방을 위한 실전교육을 받는 것을 제외하면 실제로 별도의 감염예방을 위한 교육은 찾아보기 어렵다. 2009년도에 $\mathrm{WHO}$ 는 "patient safety curriculum for medical schools'을 개발하여 의과대학 교육과정으로 환자 안전교육의 필요 성을 부각시켰다. 이 지침서에서 감염관리는 환자 안전향상을 위한 11 개의 주제 중 하나로 감염의 주요 원인 및 유형을 확인하고 의과대 학생들로 하여금 환자를 위험에 빠트릴 수 있는 행동을 인지하여 감염의 전파를 막을 수 있는 방법을 학습하는 것이 필요하다고 강조 하였다. 이렇듯 환자 안전교육과정의 필요성이 대두되고 의과대학 차원에도 인식이 확산되어가고 있으나 아직 과정을 도입하고 정착시
키기 위한 노력은 부족한 실정이다(Lee, 2009). 감염예방교육은 환 자안전의 측면에서 졸업 후 진료의 일선에서뿐만 아니라 의과대학에 서도 지속적으로 교육이 이루어져야 하는 부분으로 인식되어야 할 것이다.

본 연구는 감염성 질환에 대한 의과대학생들의 지식수준과 감염 예방교육이 개인위생 실천도에 미치는 영향에 대하여 알아봄으로써 향후 의과대학에서 지속적인 감염예방 교육프로그램 개발의 필요성 을 확인하고자 하였다. 연구결과 감염질환에 대한 지식수준이 높을 수록 개인위생 실천도가 높았으며 감염예방교육은 개인위생 실천도 를 향상시키는 데 도움이 되었다. 그러나 메르스 유행이 지역 분포도 에서 큰 차이가 있었다는 점을 고려할 때 연구자가 임의로 선정한 지역의 학생들을 대상으로 하였으며, 특히 교육 전후의 개인위생 실천도 비교는 일개 의과대학 학생만으로 진행되었기 때문에 일반화 하기는 어려울 것으로 생각된다. 향후 국내 의과대학의 감염예방교 육현황과 학생들의 개인위생 실천도에 대한 교육의 효과를 분석하는 연구들이 계속 이루어져야 할 것이다. 또한 감염예방교육의 각 항목 별로 학생들의 위생관리행태에 미치는 영향을 분석하여 반영한다면 교육의 질적 향상을 도모할 수 있을 것으로 생각된다.

\section{REFERENCES}

Al Kadi, A., \& Salati, S. A. (2012). Hand hygiene practices among medical students. Interdiscip Perspect Infect Dis, 2012, 679129.

Baker, L., Wagner, T. H., Singer, S., \& Bundorf, M. K. (2003). Use of the Internet and e-mail for health care information: Results from a national survey. JAMA, 289(18), 2400-2406.

Barroso, V., Caceres, W., Loftus, P., Evans, K. H., \& Shieh, L. (2016). Hand hygiene of medical students and resident physicians: Predictors of attitudes and behaviour. Postgrad Med J. Advance online publication. doi: 10.1136/postgradmedj-2015-133509

Calabro, K., Bright, K., \& Kouzekanani, K. (2000). Long-term effectiveness of infection control training among fourth-year medical students. Med Educ Online, 5(1), 1-7.

Ghojazadeh, M., Hajebrahimi, S., Azami-Aghdash, S., Pournaghi Azar, F., Keshavarz, M., Naghavi-Behzad, M., \& Hazrati, H. (2014). Medical students' attitudes on and experiences with evidence-based medicine: A qualitative study. J Eval Clin Pract, 20(6), 779-785.

Herbert, V. G., Schlumm, P., Kessler, H. H., \& Frings, A. (2013). Knowledge of and adherence to hygiene guidelines among medical students in Austria. Interdiscip Perspect Infect Dis, 2013, 802930.

Hwang, Y. W., Byun, J. S., Lee, K. W., Hwang, I. H., \& Kim, S. Y. (2006). Evidence based evaluation of health information in the television news. J Korean Acad Fam Med, 27(7), 523-528.

Johnston, J. M., Leung, G. M., Fielding, R., Tin, K. Y., \& Ho, L. M. (2003). The development and validation of a knowledge, attitude and behaviour questionnaire to assess undergraduate evidence-based practice teaching and learning. Med Educ, 37(11), 992-1000.

Kim, S. G. (2015). Healthcare workers infected with Middle East respiratory syndrome coronavirus and infection control. J Korean Med Assoc, 58(7), 647-654. 
Lee, J. (2015). Better understanding on MERS corona virus outbreak in Korea. J Korean Med Sci, 30(7), 835-836.

Lee, M.K., \& Kim, Y.E. (2009). A study on effects of disease information use on the internet: Based on the protection motivation theory. J Commun Sci, 9(4), 506-539.

Lee, Y. M. (2009). Patient safety curriculum in medical education. Korean J Med Educ, 21(3), 217-228.

Maggio, L. A., Tannery, N. H., Chen, H. C., ten Cate, O., \& O’Brien, B. (2013). Evidence-based medicine training in undergraduate medical education: A review and critique of the literature published 2006-2011. Acad Med, 88(7), 1022-1028.
Melenhorst, W. B., Poos, H. P., \& Meessen, N. E. (2009). Medical students need more education on hygiene behavior. Am J Infect Control, 37(10), 868-869.

Ministry of Health and Welfare. (2015, October 30). Current outbreak situation in the Republic of Korea. Retrieved from http://www.mers.go.kr/ $\mathrm{mers} / \mathrm{html} /$ jsp/main.jsp

Pittet, D. (2001). Improving adherence to hand hygiene practice: A multidisciplinary approach. Emery Infect Dis, 7(2), 234-240.

Sackett, D. L., \& Parkes, J. (1998). Teaching critical appraisal: No quick fixes. CMAJ, 158(2), 203-204. 